\title{
Lupoid Cutaneous Leishmaniasis: An Atypical and Defiant Presentation of the Disease
}

\author{
Salem Bouomrani ${ }^{1,2, *}$, Mbarka Hadded ${ }^{1,2}$
}

${ }^{1}$ Department of Internal medicine, Military Hospital of Gabes, Gabes 6000, Tunisia.

${ }^{2}$ Sfax Faculty of Medicine, University of Sfax, Sfax 3029, Tunisia.

*Corresponding Author: Salem Bouomrani, Department of Internal medicine, Military Hospital of Gabes, Gabes 6000, Tunisia.

\section{Abstract}

Cutaneous leishmaniasis (CL) is one of the most endemicand neglected diseases worldwide, still representingan important public health problem.

The clinical presentations of this infection are very polymorphic and sometimes very difficult to diagnose. Among the lesions described as "atypical" or "unusual" for $C L$, the "lupoid" form is exceptional and very defiant for clinicians in current medical practice.

We present an original case of lupoid CL with double localization on the face and the trunkin a young immuno competent Tunisian managed 33 years.

As rare as it is, this atypical clinical presentation of CL deserves to be well known by clinicians, particularly those in first line consultations in order to avoid permanent scars.

Keywords: Cutaneous leishmaniasis, Lupoidleishmaniasis, Atypical presentation,Lupus-like.

\section{INTRODUCTION}

Chroniccutaneousleishmaniasisisan anthropzoonosis still endemic in more than 88 countries around the world $[1,2]$. It is transmitted to humans through the bite of a female phlebotominesandfly infested with the parasite [3-5]. The old world leishmaniasis(Middle East, Mediterranean basin, Africa, Asia, and India)is classically opposed to that of the new world (Central and South America), depending on the species of leishmaniasis responsible for the infection [2,6]. Old world cutaneous leishmaniasis is caused mainly by four species of leishmaniasis: L.Major, L.Infantum, L.Tropica, and L.Kiliki [1-6]. The clinical presentations of this parasitosis are very polymorphic and sometimes very difficult to diagnose $[1,7,8]$. Among the lesions described as "atypical" or "unusual" for this infection, the lupus-like or "lupoid" form is exceptional and very defiant for clinicians in current medical practice $[7,9,10]$.

We present an original case report of lupoid cutaneous leishmaniasis in a young immunocompetent man.

\section{CASE REPORT}

Tunisian man, 33 years old, with no pathological medical history, was referred to our internal medicine consultation for suspicion of systemic lupus erythematosus. The diagnosis was suspected based on the finding of two erythematous, nodular, finely scaly, non-pruritic, and painless skin lesionslocated in the left cheek (Fig. 1) and in the torso (Fig. 2). These lesions had been evolving for a month.

The somatic examination did not note any other anomalies, apart from these two skin lesions.

The basic biology revealed a discrete inflammatory syndrome with an erythrocyte sedimentation rate at $42 \mathrm{mmH} 1$ and a polyclonal hypergammaglobulinemia at $19 \mathrm{~g} / \mathrm{l}$. the rest of the biological tests were within normal limits (hemoglobin, leukocytes, platelets, C-reactive protein, blood sugar, creatinine, calcemia, serum ionogram, transaminases, muscle enzymes, uric acid, lipid parameters, thyroid hormones, and analysis of urine). The anti-nuclear anti-double stranded 
DNAautoantibodies were negative, and the levels of the C3 and C4 fractions of the serum complement were conserved.

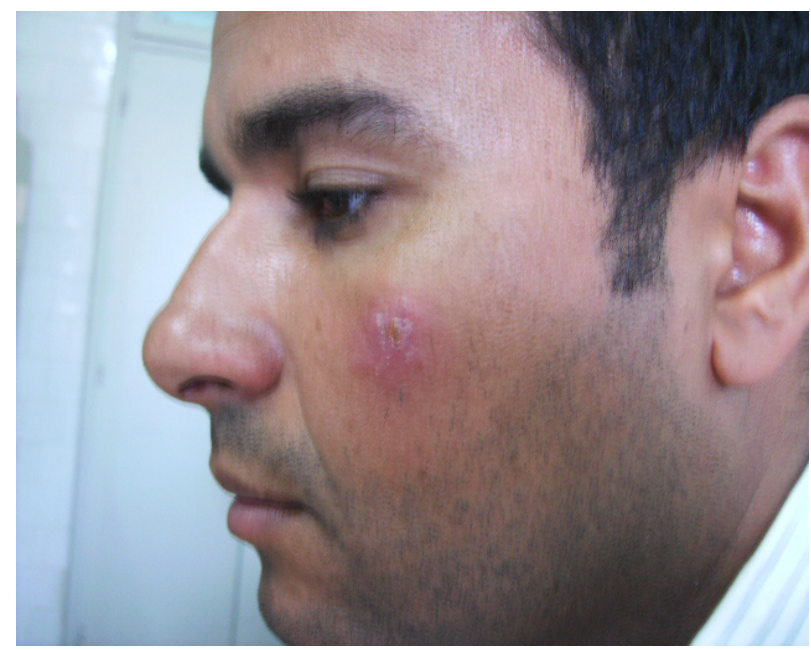

Figure 1. Erythematous, nodular, and finely scaly left malar lesion

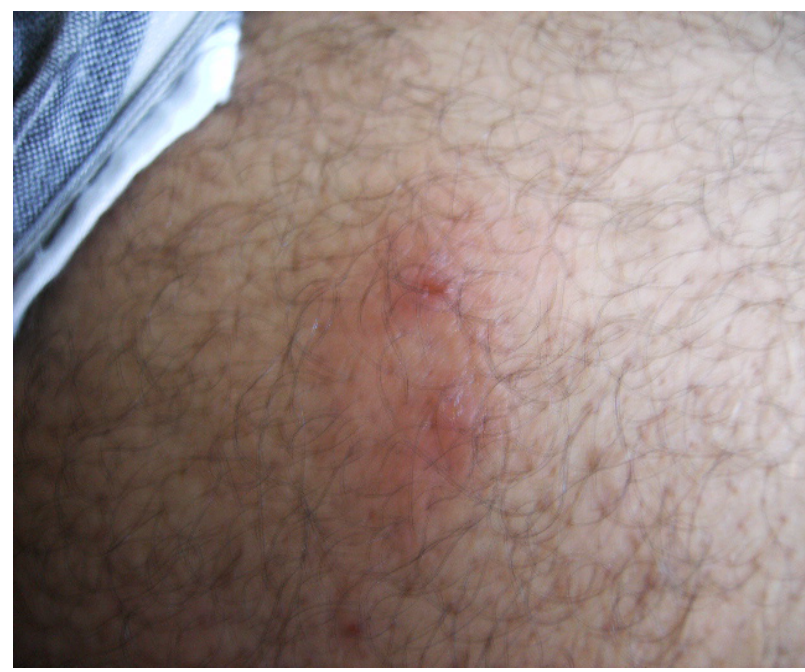

Figure 2. Erythematous and nodular lesion of the torso.

Skin biopsy of the torso lesion with direct immunofluorescence showed no lupus band. The appearance was that of a tuberculoid granuloma. Screening for tuberculosis was negative (direct examination, culture, and PCR). The direct parasitological examination concluded with the diagnosis of cutaneous leishmaniasis. Genetic typing confirmed L. Infantumtype.

Treated with intramuscular meglumineantimoniate at the dose of $60 \mathrm{mg} / \mathrm{kg} /$ day for for 10 days, the evolution was favorable with complete disappearance of the lesions. No recurrence has been noted for three years.

\section{DISCUSSION}

Cutaneous leishmaniasis is a cosmopolitan parasitic infection [3-5]. However, it remains among the most neglected diseases and represents a real public health problem in several countries of the world [4,11], although its incidence is estimated at two million cases annually [2].

The most common features of cutaneous leishmaniasis are nodular, nodulo-ulcerative, andulcero-crusted lesions [2-7]. However, the clinical presentation of this parasitosis is characterized by a large polymorphism $[2,3,7,9,11]$ with so-called "atypical" and "unusual" forms $[1,7,9]$.

Among these unusual/atypical presentations of cutaneous leishmaniasis,the following forms have been described: lupoid, sporotricoid, eczematiform, verrucous, dry, zosteriform, erysipeloid, psoriasiform, pseudotumoral, discoid lupus erythematosus-like, squamous cell carcinoma-like, erythematous volcanic ulcer, paronychial, chancriform and annular forms $[1,7,9]$. These forms are very challenging for clinicians, particularly those in the first line and in non-endemic countries [4].

The clinical aspect depends on two main factors which are the species of leishmania responsible for the infection and the quality of the host's immune response $[3,6,7]$.

Described for the first time by Christopherson in 1923 [12], the lupoid form is an exceptional and unusual clinical presentation of cutaneous leishmaniasis $[7,9,10]$. It was called lupoid because the clinical presentation of the skin lesion, particularly on the face, reminded of lupus vulgaris (cutaneous tuberculosis) [9-12].

Its prevalence is estimated at $0.5-6.2 \%$ depending on the series $[10,13,14]$. The majority of cases are reported in the form of sporadic clinical cases $[10,14,15]$ or in small series not exceeding sixteen cases $[9,13]$. It remains, however, the most frequent of the atypical presentations of cutaneous leishmaniasis [16].

The lesion is typically unique, and the face (over the nose and the cheeks) represents its preferred location $[9,10,13,14]$; exceptionally lupoid forms of cutaneous leishmaniasis have been reported in the elbow [9].

Immunosuppression seems to play an important role in some atypical and unusual morphological variants of the disease like lupoid form [1]. 
The differential diagnosis of lupoidleishmaniasis is mainly made with lupus vulgaris, lupus erythematosus, lupus pernio (form of cutaneous sarcoidosis), and facial erysipelas. [15]. This diagnosis is all the more difficult to make since the occurrence of lupoidleishmaniasis has been reported in patients living in nonendemic area[15].

\section{Conclusion}

As rare as it is, this atypical clinical presentation of cutaneous leishmaniasis deserves to be well known by clinicians, particularly those in first line consultations. This improved knowledge is the only guarantor of early diagnosis and appropriate management, in order to avoid permanent scars. Our observation is characterized by the multiple character of the lesions, the double localization on the face and the trunk, andthe patient's immunocompetent status.

\section{REFERENCES}

[1] Meireles CB, Maia LC, Soares GC, Teodoro IPP, Gadelha MDSV, da Silva CGL, et al. Atypical presentations of cutaneous leishmaniasis: A systematic review. Acta Trop. 2017;172:240-254.

[2] Galluzzo CW, Eperon G, Mauris A, Chappuis F. Leishmaniose cutanée de l’Ancien Monde [Old World cutaneousleishmaniasis]. Rev Med Suisse. 2013;9(385):990-995.

[3] Mokni M. Cutaneous leishmaniasis. Ann DermatolVenereol. 2019;146(3):232-246.

[4] Laboudi M, Sahibi H, Elabandouni M, Nhammi H, AitHamou S, Sadak A. A review of cutaneous leishmaniasis in Morocco: A vertical analysisto determine appropriate interventions for control and prevention. Acta Trop. 2018;187:275-283.

[5] Burnett MW. Cutaneous leishmaniasis. J Spec Oper Med. 2015;15(1):128-129.

[6] Hengge UR, Marini A. Cutaneousleishmaniasis. Hautarzt. 2008;59(8):627-632.
[7] Remadi L, Haouas N, Chaara D, Slama D, Chargui $\mathrm{N}$, Dabghi R, et al. Clinical Presentation of Cutaneous Leishmaniasis caused by Leishmania major. Dermatology. 2016;232(6):752-759.

[8] García-Almagro D. Cutaneous leishmaniasis. ActasDermosifiliogr. 2005;96(1):1-24.

[9] Masmoudi A, Boudaya S, Ayadi N, Bouassida S, Khabir A, Meziou TJ, et al. Clinical and histological studyoflupoidcutaneousleishmaniasis(16cases). Presse Med. 2007;36(12 Pt 1):1738-1742.

[10] Khaled A, Goucha S, Trabelsi S, Zermani R, Fazaa B. Lupoid cutaneous leishmaniasis: a case report. DermatolTher (Heidelb). 2011;1(2):36-41.

[11] Reithinger R, Dujardin JC, Louzir H, Pirmez C, Alexander B, Brooker S. Cutaneous leishmaniasis. Lancet Infect Dis. 2007;7(9):581-596.

[12] Christopherson JB. Lupus leishmaniasis: a leishmaniasis of the skin resembling lupus vulgaris: hitherto unclassified. British journal of dermatology, 1923, 35:123-31.

[13] Ul Bari A, Raza N. Lupoid cutaneous leishmaniasis: a report of 16 cases. Indian J DermatolVenereolLeprol. 2010;76(1):85.

[14] Sadeghian G, Ziaei H, Shirani-Bidabadi L, Nilforoushzadeh MA. Lupoidleishmaniasis due to Leishmania major with remaining large scars: report of 2 cases. East MediterrHealth J. 2010;16(3):344-345.

[15] Gupta LK, Meena S, Khare AK, Balai M, Mittal A, Mehta S. Lupoid cutaneous Leishmaniasis: A Report of Three Cases from Nonendemic Area. Indian J Dermatol. 2017;62(5):548.

[16] Bari A, Rahman SB. Many faces of cutaneous leishmaniasis. Indian J DermatolVenereolLeprol 2008;74:23-7

Citation: Salem Bouomrani, Mbarka Hadded. Lupoid Cutaneous Leishmaniasis: An Atypical and Defiant Presentation of the Disease. Archives of Dermatology and Skin Care. 2020; 3(1): 07-09

Copyright: (C) 2020 Salem Bouomrani, Mbarka Hadded. This is an open access article distributed under the Creative Commons Attribution License, which permits unrestricted use, distribution, and reproduction in any medium, provided the original work is properly cited.

Archives of Dermatology and Skin Care V3 . I1 . 2020 